\title{
O Desenvolvimento da Autonomia Discente nas Aulas de Italiano como Língua Adicional
}

\author{
Daniela Aparecida Vieira*
}

RESUMO: Segundo Freire (1996), Mezzadri (2003) e Kumaravadivelu (2006), um dos principais escopos do processo de ensino-aprendizagem é promover a autonomia dos alunos. Diante disso, este artigo tem como objetivo apresentar reflexões, de caráter teórico e prático, sobre a importância do desenvolvimento da autonomia discente nas aulas de italiano como língua adicional. No que concerne aos aspectos teóricos, serão tratadas algumas definições de autonomia em âmbito didático-pedagógico. Em seguida, serão abordadas as noções de língua estrangeira, segunda língua e língua adicional, procurando-se explicar por que, neste texto, optou-se pelo último termo. Quanto aos aspectos práticos, serão mostrados alguns dados de um estudo de caso realizado no primeiro semestre de 2015 em uma sala de aula do Italiano no Campus, curso de extensão da Faculdade de Filosofia, Letras e Ciências Humanas da Universidade de São Paulo. A análise dos dados, realizada à luz dos postulados teóricos tratados neste artigo, parece indicar que, durante as aulas, os estudantes puderam construir conhecimentos na e sobre a língua italiana e, ao mesmo tempo, refletir sobre o seu próprio processo de aprendizagem linguística, o que provavelmente contribuiu para os discentes se tornarem mais autônomos.

PALAVRAS-CHAVE: ensino-aprendizagem; italiano como língua adicional; autonomia discente.

ABSTRACT: Secondo Freire (1996), Mezzadri (2003) e Kumaravadivelu (2006), uno dei principali scopi del processo di insegnamento-apprendimento è quello di promuovere l'autonomia degli alunni. In base a questa idea, l'obiettivo del presente articolo è quello di presentare riflessioni teoriche e pratiche sull'importanza dello sviluppo dell'autonomia del discente nelle lezioni di italiano come lingua aggiuntiva. Per quanto riguarda gli aspetti teorici verranno presentate alcune definizioni di autonomia nell'ambito didattico-pedagogico. Inoltre verranno discusse le nozioni di lingua stra-

*Pontifícia Universidade Católica, São Paulo (Brasil) — daniela.apvieira@yahoo.com.br DOI: http://dx.doi.org/10.11606/issn.2238-8281.v0i36p5-16 
niera, seconda lingua e lingua aggiuntiva e si cercherà di spiegare perché in questo testo si è scelto di usare l'ultimo termine. Riguardo agli aspetti pratici verranno esposti alcuni dati di uno studio di caso realizzato nel primo semestre del 2015 in una classe dell'Italiano nel Campus, corso libero della Facoltà di Filosofia, Lettere e Scienze Umane dell'Università di San Paolo. L'analisi dei dati, basata sugli aspetti teorici trattati in questo articolo, sembra indicare che nelle lezioni gli studenti abbiano potuto costruire conoscenze in italiano e su questa lingua e allo stesso tempo riflettere sul proprio processo di apprendimento linguistico. Ciò probabilmente ha fatto sì che gli allievi diventassero più autonomi.

PAROLE-CHIAVE: insegnamento-apprendimento; italiano come lingua aggiuntiva; autonomia del discente.

ABSTRACT: According to Freire (1996), Mezzadri (2003), and Kumaravadivelu (2006), one of the most important goals of teaching and learning process is to promote learners' autonomy. Therefore, this paper aims to present theoretical and practical reflections on the importance of the development of students' autonomy in Italian classes (Italian as an additional language). Regarding the theoretical aspects, some definitions of autonomy in didactic-pedagogical context will be addressed. After that, the notions of foreign language, second language, and additional language will be addressed, and we will explain why, in this text, the last term was chosen. Regarding the practical aspects, we will show some data from a case study carried out during the first semester of 2015 at "Italian on Campus", a university extension course offered by the Faculty of Philosophy, Languages and Human Sciences of the University of São Paulo. The analysis of the data collected, which was based on the theoretical postulates discussed in this paper, seems to indicate that, during the classes, students could construct knowledge in Italian and about this language, and, at the same time, they could reflect on their own process of linguistic learning. That has probably helped students to become more autonomous.

KEYWORDS: teaching and learning; Italian as an additional language; learner's autonomy. 


\section{Introdução}

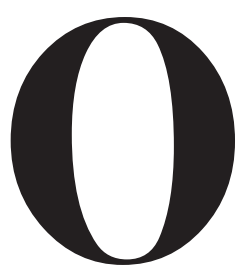

presente artigo tem como objetivo apresentar reflexões teóricas e práticas acerca da relevância do desenvolvimento da autonomia discente nas aulas de italiano como língua adicional.

Para atingir esse propósito, este artigo está dividido em duas seções. Na primeira, em que são desenvolvidas reflexões teóricas, discutem-se algumas definições de autonomia em âmbito educacional, buscando-se similaridades entre elas. Em seguida, abordam-se as noções de língua estrangeira (LE), segunda língua (L2) e língua adicional (LA). Na segunda, em que são tratados aspectos práticos, mostram-se alguns dados de um estudo de caso realizado no primeiro semestre de 2015 numa sala de aula do Italiano no Campus, curso de extensão da Faculdade de Filosofia, Letras e Ciências Humanas da Universidade de São Paulo ${ }^{1}$ (FFLCH-USP).

A análise dos dados coletados, realizada à luz dos postulados teóricos supracitados, sugere que, durante as aulas, os discentes puderam construir conhecimentos na e sobre a língua italiana e, ao mesmo tempo, refletir sobre o seu próprio processo de aprendizagem da LA, o que provavelmente contribuiu para que os alunos se tornassem mais autônomos.

\section{Algumas definições de autonomia e a definição de língua adicional}

Em 1996, o grande educador brasileiro Paulo Freire publicou o livro Pedagogia da autonomia - Saberes necessários à prática educativa. Nessa obra, o autor propõe que a autonomia seja vista como um processo de amadurecimento do ser, isto é, ele não a considera um processo vinculado apenas à educação, mas também à vida em geral. Ele explica que a autonomia se constitui na experiência de várias decisões que vão sendo tomadas e se funda na responsabilidade, a qual vai sendo construída durante esse processo. Em âmbito educacional, a partir dessa explicação, parece possível dizer que a autonomia consista, de certo modo, em assumir a responsabilidade pela própria aprendizagem. Segundo esse autor, uma das tarefas centrais do professor é

apoiar o educando para que ele mesmo vença suas dificuldades na compreensão ou na inteligência do objeto e para que sua curiosidade,

1 Neste artigo, apresento uma parte da pesquisa que resultou em minha tese de doutorado, defendida junto à FFLCH-USP em 23 de novembro de 2017. A tese intitula-se Dos estilos e estratégias de aprendizagem à didatização de materiais para o ensino do italiano língua estrangeira na pedagogia pós-método e foi desenvolvida sob a orientação da professora Dra. Paola Giustina Baccin. 
compensada e gratificada pelo êxito da compreensão alcançada, seja mantida e, assim, estimulada a continuar a busca permanente que o processo de conhecer implica (FREIRE, 1996, p. 116).

A partir desse postulado, pode-se dizer que o educador brasileiro considera o desenvolvimento da autonomia dos alunos como uma das tarefas primordiais do docente. Uma definição de autonomia que dialoga com a de Freire (1996), mas que se refere, especificamente, à área de didática das línguas, é a de Mezzadri (2003). O autor italiano afirma que a autonomia discente está relacionada à participação ativa do estudante nas decisões concernentes ao seu percurso de formação. Visando fomentar essa participação do aprendiz, é relevante e necessário que o professor tente sensibilizar o aluno quanto às diferentes maneiras de se aprender uma língua e fazê-lo refletir sobre elas. A autonomia do discente é, portanto, em larga medida, resultante de um processo de ensino, e o professor deve agir nesse âmbito tendo plena consciência de seu papel. Assim, para que o aprendiz desenvolva a autonomia, é indispensável a contribuição do professor, que age para determinar e desenvolver, em colaboração com o aluno, objetivos e estratégias de aprendizagem.

Outra definição de autonomia que vai ao encontro dos postulados de Freire (1996) e Mezzadri (2003) é a de Leffa (2003). Segundo esse autor brasileiro, a autonomia consiste em um estágio a que se chega: durante um período de seu percurso de aprendizagem, o aluno precisará ser auxiliado pelo professor, mas é esperado que, após algum tempo, o estudante seja “capaz de executar a tarefa por conta própria" (LEFFA, 2003, p. 5). No tocante ao ensino-aprendizagem de línguas, esse teórico ressalta que só é possível aprender outra língua se o discente for autônomo e que, "na aprendizagem autônoma, a responsabilidade está no aluno" (LEFFA, 2003, p. 9).

Um teórico italiano cujas concepções também dialogam com as dos autores supracitados é Borneto (1998). Para ele, a autonomia é a capacidade de aceitar responsabilidades por todas as decisões que se referem à própria aprendizagem e seguir os passos necessários para que sejam tomadas tais decisões.

Algumas dessas definições de autonomia e muitas outras são discutidas por Paiva (2006) no artigo intitulado "Autonomia e complexidade". A autora brasileira, após apresentar, problematizar e comentar criticamente diversas definições, expõe a sua concepção de autonomia, definindo-a como "um sistema sociocognitivo complexo, que se manifesta em diferentes graus de independência e controle sobre o próprio processo de aprendizagem" (PAIVA, 2006, p. 88).

O conceito de autonomia é discutido, também, por Kumaravadivelu (2006), que, ao propor a pedagogia pós-método, estabelece dez macroestratégias, isto é, planos gerais de ensino. Uma dessas macroestratégias consiste em promover a autonomia do aprendiz. O teórico indiano afirma que a pedagogia pós-método leva em consideração duas visões de autonomia discente: uma estrita e uma ampla.

A primeira procura desenvolver, nos estudantes, a capacidade de "aprender a aprender", 
ou seja, a capacidade de escolher e usar estratégias apropriadas para atingir os objetivos de aprendizagem desejados, para monitorar seu processo de aprendizagem e para maximizar seu potencial de aprendizagem. Esse autor sugere que, nas aulas de língua, o professor crie oportunidades para que os alunos possam identificar seus estilos e estratégias de aprendizagem.

A segunda vai além da capacidade de "aprender a aprender" e inclui a capacidade de aprender a libertar-se, ou seja, a capacidade dos aprendizes de pensar criticamente para identificar impedimentos sociopolíticos que os impossibilitam de desenvolver seu pleno potencial humano. É relevante salientar que, no presente artigo, ao discorrer sobre a prática embasada por esses postulados teóricos, procurarei exemplificar apenas o desenvolvimento da autonomia estrita.

Antes, porém, de expor minhas reflexões de cunho prático, abordarei outro conceito muito importante neste estudo: o conceito de língua adicional. Convém ressaltar que, na literatura da área de ensino-aprendizagem da língua italiana, o termo LA raramente é utilizado. Nessa área, costumam ser empregados os termos LE e L2, os quais, segundo Balboni (1999), designam respectivamente: a língua aprendida, geralmente, em um contexto de educação formal, em um lugar onde ela não tem o status de língua oficial (exemplo: o italiano aprendido por brasileiros em seu próprio país); a língua aprendida em um contexto de imersão, num espaço em que ela tem o status de língua oficial (exemplo: o italiano aprendido por brasileiros na Itália).

O termo língua adicional, por sua vez, de acordo com Leffa e Irala (2014), refere-se à língua que o aluno aprende por acréscimo e que tem, portanto, como ponto de partida, outras línguas que o discente já conhece. Os dois autores afirmam que, como o ensino da LA parte da primeira língua do aprendiz, há uma tendência "de se valorizar o contexto do aluno, desde suas práticas sociais, os valores de sua comunidade e uma visão crítica da aprendizagem da língua" (LEFFA e IRALA, 2014, p. 22). Eles esclarecem, também, que o termo LA é preferível aos termos LE e L2, porque o primeiro funda-se, essencialmente, em critérios geográficos, e o segundo está relacionado tanto a esses critérios quanto à sequência de aprendizagem das línguas.

Embora se saiba que o termo LA não costuma ser utilizado na área de didática da língua italiana, com base em Leffa e Irala (2014), proponho que ele seja empregado nesse âmbito, porque o termo LA evidencia uma concepção heteroglóssica de língua (BAKHTIN, 1981), ou seja, uma visão segundo a qual as línguas aprendidas pelo sujeito não estão separadas dentro dele; elas estão entrelaçadas, estabelecem um diálogo entre si e são interdependentes. O emprego dos termos LE e L2, por sua vez, parece remeter a uma visão monoglóssica de língua.

\section{Um estudo de caso realizado com estudantes do Italiano no Campus}

Pautando-me no arcabouço teórico tratado na seção anterior, realizei, com os meus alunos do Italiano no Campus (IC), um trabalho didático-pedagógico que tinha como um de seus objetivos o desenvolvimento da autonomia discente nas aulas de italiano como LA. O IC era um curso de extensão universitária da FFLCH-USP no qual eram ministradas aulas de italiano 
aos estudantes, funcionários e professores dessa universidade e à comunidade externa. $\mathrm{O}$ curso era destinado apenas a jovens e adultos que tivessem concluído, no mínimo, o ensino médio. Dividia-se em oito níveis de 45 horas cada, sendo ministrado por graduandos e pós-graduandos em Letras (Italiano) da FFLCH-USP. Infelizmente, por problemas de ordem burocrático-administrativa, o curso foi suspenso em julho de 2015 e, por enquanto, não há previsão de que seja retomado.

O trabalho que realizei com os estudantes fez parte de minha pesquisa de doutorado, e os dados analisados na pesquisa, os quais apresento, parcialmente, neste artigo, foram coletados durante todo o primeiro semestre de 2015 em uma turma de nível II do IC.

Esse grupo era composto por dez aprendizes (seis mulheres e quatro homens), cujas idades variavam entre 22 e 61 anos. A turma era bastante heterogênea quanto à faixa etária, às áreas de formação acadêmica e às profissões, mas possuía muitos interesses em comum: por exemplo, todos os alunos gostavam da música italiana e estudavam essa LA, sobretudo, pelo prazer de aprendê-la. Ademais, todos os discentes, antes de iniciar o percurso de aprendizagem do italiano, já tinham estudado outras línguas adicionais.

Como a pesquisa foi realizada em minha própria sala de aula, desempenhei, concomitantemente, o papel de professora e de pesquisadora, corroborando a inseparabilidade entre o ensino e a pesquisa, ideia defendida por Freire (1996), Kumaravadivelu (2006), Martins e Varani (2012), entre outros autores.

O estudo realizado no Italiano no Campus consistiu em uma pesquisa qualitativa, situada no paradigma interpretativista, podendo ser considerada um estudo de caso, que, segundo Leffa (2006, p. 14), "é a investigação profunda e exaustiva de um participante ou pequeno grupo". Amado (2009) explica que o estudo de caso também pode visar à promoção de mudanças. Dessa forma, na pesquisa realizada, por meio da investigação de singularidades dos alunos (sobretudo de seus estilos e estratégias de aprendizagem), uma das mudanças que se buscou promover diz respeito ao desenvolvimento da autonomia estrita dos aprendizes (KUMARAVADIVELU, 2006), que se refere ao "aprender a aprender" línguas, isto é, ao desenvolvimento de reflexões sobre diferentes maneiras de aprender uma LA, que podem contribuir para que os estudantes se conscientizem das formas pelas quais eles a aprendem e dos modos pelos quais podem aprendê-la melhor, tanto nas aulas quanto fora delas.

\subsection{Os questionários utilizados na pesquisa}

Para fazer a parte da pesquisa apresentada neste artigo, utilizei, como instrumentos de coleta de dados, dois questionários: um sobre estilos de aprendizagem e outro sobre estratégias de aprendizagem de línguas. Além disso, também fiz entrevistas individuais com os alunos. $\mathrm{O}$ primeiro questionário ${ }^{2}$ foi elaborado por Mariani (2000), e o segundo - que, na verdade, é um inventário $^{3}$ de estratégias - foi elaborado por Oxford (1989). Esse inventário foi, originalmente, escrito em inglês e, para usá-lo na sala de aula não só como instrumento de coleta de dados, mas

2 Disponível em: $<$ http://www.learningpaths.org/Questionari/stiliappr.avvertenze.htm> Acesso em 27 mar. 2018.

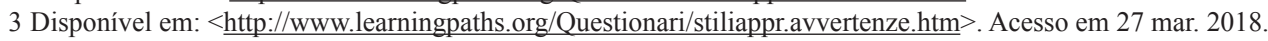


também como material para as aulas, eu o traduzi para o italiano.

O objetivo do primeiro questionário consistia em possibilitar que os alunos refletissem sobre as diversas formas pelas quais eles aprendem línguas. Para desenvolver tais reflexões, além de responderem o questionário, os estudantes fizeram atividades de interpretação das respostas, as quais foram realizadas em duplas e discutidas com o grupo todo. Essas atividades didáticas foram elaboradas em italiano, e preparei-as, intencionalmente, na LA, para que elas se tornassem, de certo modo, um material para as aulas. Por sua vez, o escopo do segundo questionário consistia em fomentar reflexões e discussões acerca das diferentes estratégias que se podem usar para aprender uma LA.

Os discentes responderam esses dois questionários durante as aulas, e, com base em ambos, fizemos, em italiano, atividades que lhes possibilitassem refletir sobre como eles aprendem uma LA e sobre o que poderiam fazer para aprendê-la melhor. Duas dessas atividades foram: uma lista coletiva de estratégias de aprendizagem de línguas e um jogo relativo a tais estratégias.

No que concerne à lista coletiva de estratégias de aprendizagem, pode-se dizer que ela resultou de um processo de discussão, na LA, sobre essas estratégias e de colaboração entre todos os membros do grupo. A lista foi escrita pelos discentes e organizada por mim com base nas respostas deles a esta questão: “C'è qualche strategia che usi per imparare l'italiano e che non è stata menzionata nella lista scritta da Oxford (1989)? Quale?". Entre as estratégias mencionadas pelos discentes estavam as seguintes:

- ascoltare e imparare a memoria alcune canzoni italiane;

- scrivere una parola o una frase diverse volte per memorizzarla;

- impostare l'italiano come lingua predefinita del computer (ad esempio su Windows o su internet);

- scaricare applicazioni e giochi in italiano sul cellulare, computer o tablet;

- cercare un amico di penna (un parlante di italiano).

\subsection{Algumas atividades didáticas quanto ao "aprender a aprender" lín-} guas

É interessante notar que algumas das estratégias mencionadas pelos aprendizes referem-se ao uso de instrumentos tecnológicos, que, provavelmente, não foram colocados pela professora Oxford, em seu inventário de estratégias de aprendizagem de línguas, porque, em 1989, ano em que o questionário foi publicado por ela, alguns desses recursos tecnológicos (os tablets, por exemplo) ainda não existiam.

Também é interessante notar que, enquanto alguns alunos citaram estratégias que envolvem o uso da internet, do computador etc., outros mencionaram estratégias que se baseiam em atividades sociais raramente realizadas nos dias hodiernos, como a escrita de cartas. Atualmente, em geral, poucas pessoas escrevem cartas pessoais, contudo, ainda assim, um dos estudantes 
afirmou que, a seu ver, ter, como amigo por correspondência, um falante de italiano seria uma estratégia de aprendizagem da língua adicional.

Por meio dessa lista coletiva de estratégias de aprendizagem, também é possível identificar a concepção de aprendizagem de alguns discentes: alguns deles, por exemplo, mencionaram a repetição e a memorização como estratégias que eles empregavam para aprender melhor o italiano. Isso parece indicar que, para eles, a aprendizagem da LA ainda está muito vinculada à educação tradicional e behaviorista, segundo a qual, repetir e memorizar determinados conteúdos podem ser os principais modos de aprendê-los.

Parece ser inquestionável o fato de que tal concepção seja decorrente da própria formação dos estudantes, que tiveram, em sua vida escolar/acadêmica (em boa parte dela, ou, talvez, em toda a sua vida), um papel predominantemente passivo, no qual lhes cabia, sobretudo, memorizar conteúdos para, posteriormente, reproduzir nas avaliações (que, geralmente, consistiam em provas escritas) o que foi memorizado.

No tocante ao jogo sobre estratégias de aprendizagem, pode-se afirmar que ele foi elaborado com o escopo de contribuir para que os estudantes refletissem sobre como eles poderiam melhorar a própria aprendizagem da língua italiana. Trata-se de um jogo de percurso que confeccionei para os discentes com base no inventário de estratégias de aprendizagem de línguas de Oxford (1989) e em discussões, que realizamos na sala de aula, sobre as estratégias que os alunos costumavam empregar para aprender italiano e outras línguas adicionais.

O jogo era constituído por um tabuleiro, vinte cartas com perguntas de múltipla escolha (escritas em italiano) referentes a estratégias de aprendizagem de línguas, um dado e quatro peões coloridos (um para cada estudante). Para jogá-lo, os estudantes deveriam se organizar em grupos de, no máximo, quatro componentes e decidir qual dos discentes iniciaria a atividade. Em seguida, esse aluno deveria jogar o dado para saber o número de casas que ele poderia avançar no percurso. Mas, antes de avançar no percurso, o estudante deveria responder uma pergunta feita por um dos colegas (o qual deveria escolher, aleatoriamente, uma das cartas e ler, em voz alta, a pergunta contida nela, juntamente com as três respostas). Se esse aluno respondesse corretamente, ou seja, se ele desse, como resposta, a estratégia mais adequada à situação descrita na carta lida por seu colega (assinalada em vermelho), ele poderia avançar, no tabuleiro, o número de casas mostrado no dado que ele tinha jogado. Se, contudo, ele errasse a resposta, isto é, se ele desse, como resposta, uma estratégia de aprendizagem inadequada, deveria permanecer na casa onde ele estivesse. Assim, neste jogo, todos os aprendizes deveriam fazer perguntas uns aos outros, e o vencedor seria aquele que chegasse, primeiro, ao final do percurso.

No fim do semestre letivo, foram feitas entrevistas individuais com os alunos, visando possibilitar-lhes avaliar todo o trabalho didático-pedagógico realizado no decorrer das aulas. As suas respostas às questões que lhes foram feitas durante as entrevistas evidenciaram que o questionário sobre estilos de aprendizagem (MARIANI, 2000), o inventário de estratégias de aprendizagem de línguas (OXFORD, 1989), as atividades e as discussões decorrentes desses dois instrumentos de coleta de dados possibilitaram aos estudantes o desenvolvimento de re- 
flexões sobre as maneiras pelas quais eles aprendem uma língua adicional e sobre o que eles poderiam fazer para aprendê-la melhor. A seguir, são transcritas duas dessas respostas:

"Acho que foi um trabalho muito bom e muito interessante, porque, conhecendo melhor o meu modo de aprender e diferentes estratégias de aprendizagem de línguas, posso aprender melhor o italiano. Mesmo sendo professora, eu nunca tinha parado para pensar nisso. Achei esse trabalho tão legal que estou pensando em fazer com meus alunos também" (Simone ${ }^{4}, 44$ anos, professora de História e de Informática na rede pública municipal de ensino de São Paulo).

"É uma oportunidade que a gente tem para se conhecer também, porque, às vezes, você pensa que só estudando, lendo e praticando exercício escrito, você está aprendendo... Também! Mas não é tudo, e talvez a gente não conhecesse outras estratégias, o que a pesquisa fez com que a gente descobrisse. Eu, mesmo sendo da área de Educação, eu desconhecia. Então, acho esse trabalho extremamente válido, porque é um além do que simplesmente ter aula de italiano, é um além que você tem e você percebe onde você pode estar buscando novas formas de aprender" (Fernando, 29 anos, professor de Filosofia na rede pública estadual de ensino de São Paulo).

A resposta de Simone parece mostrar que ela tinha a intenção de partilhar, com os seus alunos, o que ela aprendeu, levando essas reflexões para outras salas de aula, para outros aprendizes, que talvez também as levem para outras pessoas. Já a resposta de Fernando parece indicar que, para ele, o trabalho didático-pedagógico realizado foi significativo, porque lhe possibilitou não só aprender a língua italiana, como também descobrir novas estratégias de aprendizagem dessa LA.

Com base em algumas das definições de autonomia expostas neste capítulo e, sobretudo, na definição de autonomia estrita, proposta por Kumaravadivelu (2006), pode-se afirmar que o trabalho didático-pedagógico realizado com os alunos do IC ajudou-os a refletir sobre o "aprender a aprender", ou seja, ajudou-os a identificar os seus próprios estilos e estratégias de aprendizagem, bem como selecionar e utilizar estratégias adequadas para alcançar os objetivos de aprendizagem desejados por eles.

As reflexões que os estudantes desenvolveram a partir desse trabalho não se limitaram às aulas: o nosso curso terminou no fim de junho de 2015, mas, mesmo após o término das aulas, alguns discentes continuaram compartilhando, por meio de nossa lista de e-mails do grupo, estratégias de aprendizagem que eles utilizavam e/ou descobriram, o que fez com que a nossa lista coletiva de estratégias de aprendizagem de línguas aumentasse. Ademais, em setembro de 2016, isto é, mais de um ano após a conclusão do curso, recebi um e-mail de um dos alunos em que ele me relatou que, pensando sobre o que tínhamos estudado juntos, ele mesmo tinha decidido elaborar uma atividade didática para o seu estudo autônomo.

Por ocasião das Olimpíadas realizadas no Rio de Janeiro em 2016, o objetivo do estudante era aprender os nomes de esportes olímpicos em italiano. Para isso, ele pesquisou os nomes desses esportes e elaborou, para si mesmo, um jogo ${ }^{5}$ com tais nomes e imagens que os representavam. Entretanto, ele não guardou essa atividade didática para si, ele me enviou o jogo para

4 Os nomes dos estudantes são fictícios e foram escolhidos por eles mesmos, para que a sua identidade fosse preservada na pesquisa.

5 Para ver o jogo elaborado pelo estudante, bem como as demais atividades didáticas mencionadas, pode-se consultar 
que eu o usasse como material nas aulas, compartilhando-o com outros discentes. Foi muito gratificante saber que o trabalho desenvolvido nas aulas parece ter, de certo modo, incentivado o aprendiz não só a continuar estudando a língua italiana fora da sala de aula, mas também a preparar o seu próprio material.

A meu ver, mesmo sendo inusual, a preparação de materiais pelos estudantes consiste em um exercício de autonomia, no qual o aluno se torna tão responsável por sua aprendizagem, que ele mesmo busca produzir materiais que serão mediadores entre ele e o conhecimento que ele deseja construir.

Portanto, a partir da análise dos dados coletados na pesquisa, realizada à luz dos postulados teóricos tratados neste artigo, pode-se asseverar que trazer para a sala de aula reflexões, discussões e materiais sobre estilos e estratégias de aprendizagem de línguas consiste em uma das maneiras de contribuir para o desenvolvimento da autonomia discente.

\section{Considerações finais}

Neste artigo, foram apresentadas reflexões, de cunho teórico e prático, sobre o desenvolvimento da autonomia dos alunos no processo de ensino-aprendizagem de italiano como língua adicional.

No que concerne aos aspectos teóricos, procurou-se mostrar que há diversas definições de autonomia e que a maioria delas têm um ponto em comum: ressaltam a importância de o estudante se responsabilizar por sua aprendizagem (FREIRE, 1996; MEZZADRI, 2003; LEFFA, 2003; BORNETO, 1998). Alguns autores que discorrem acerca da autonomia também salientam a relevância do papel do professor nesse processo, explicando que compete ao docente auxiliar os alunos de modo a contribuir para que eles se conscientizem das formas pelas quais eles aprendem e para que definam e desenvolvam estratégias de aprendizagem adequadas aos objetivos que eles desejam alcançar (MEZZADRI, 2003; LEFFA, 2003).

No tocante aos aspectos práticos, ao se apresentarem alguns dados coletados numa turma de alunos iniciantes no estudo da língua italiana, foram expostas algumas reflexões e atividades (produção de uma lista coletiva de estratégias de aprendizagem de línguas e jogo sobre estratégias) que visavam ao desenvolvimento da autonomia estrita dos discentes (KUMARAVADIVELU, 2006). Essas reflexões, que foram feitas junto com os aprendizes, e essas atividades podem ser consideradas maneiras de incentivar os estudantes a pensarem sobre os modos pelos quais eles aprendem uma LA e a buscarem diferentes formas de melhorar a própria aprendizagem.

Os dados analisados sugerem que até mesmo os alunos adultos (que já têm muitas experiências com a aprendizagem em geral e com a aprendizagem de línguas) consideram relevante que a sala de aula de línguas adicionais seja um espaço para que eles construam conhecimentos não apenas na e sobre a LA, mas também sobre diversas formas de aprendê-la.

minha tese de doutorado, disponível na Biblioteca Digital da Universidade de São Paulo (http://www.teses.usp.br/ teses/disponiveis/8/8148/tde-02042018-113648/pt-br.php). 
Em suma, os dados expostos neste artigo, analisados à luz dos postulados teóricos que o alicerçam, parecem indicar que o "aprender a aprender" pode e deve ser trabalhado nas aulas de línguas adicionais, pois pode fomentar o desenvolvimento da autonomia dos discentes, que, ao assumirem a responsabilidade pela própria aprendizagem, passam a ter um papel mais ativo no processo de ensino-aprendizagem da LA. Desenvolver a autonomia nas aulas de LA pode ser uma das maneiras de tentar garantir que todos os estudantes tenham oportunidades de aprendizagem e possam se responsabilizar, cada vez mais, por ela.

\section{Referências}

AMADO, J. da S. Introdução à investigação qualitativa em educação. Coimbra: Universidade de Coimbra, 2009.

BAKHTIN, M. Discourse in the novel. In: HOLQUIST, M. (org.). The dialogic imagination. University of Texas Press, 1981, p. 259-422.

BALBONI, P. Dizionario di Glottodidattica. Perugia: Guerra Edizioni, 1999.

BORNETO, C. S. (org.). C'era una volta il metodo. Tendenze attuali nella didattica delle lingue straniere. Roma: Carocci, 1998.

FREIRE, P. Pedagogia da autonomia - Saberes necessários à prática educativa. Rio de Janeiro: Paz e Terra, 1996.

KUMARAVADIVELU, B. Understanding Language Teaching: from Method to Postmethod. Mahwah, New Jersey: Lawrence Erlbaum Associates, 2006.

LEFFA, V. J. Aprendizagem de línguas mediada por computador. In: LEFFA, V. J. (org.). Pesquisa em Linguística Aplicada - Temas e Métodos. Pelotas: Educat, 2006, p. 5-30.

. Quando menos é mais: a autonomia na aprendizagem de línguas. In: NICOLAIDES, C. (org.). O desenvolvimento da autonomia no ambiente de aprendizagem de línguas estrangeiras. Pelotas: UFPEL, 2003, p. 33-49.

; IRALA, V. B. O ensino de outras línguas na contemporaneidade: questões conceituais e metodológicas. In: LEFFA, V. J.; IRALA, V. B. (orgs.). Uma espiadinha na sala de aula: ensinando línguas adicionais no Brasil. Pelotas: Educat, 2014.

MARIANI, L. Portfolio. Strumenti per documentare e valutare cosa si impara e come si impara. Bologna: Zanichelli, 2000.

MARTINS, M. F.; VARANI, A. Professor e pesquisador: considerações sobre a problemática relação entre ensino e pesquisa. In: Revista Diálogo Educ. Curitiba, 2012, v. 12, n 37, p. 647-680. Disponível em: $<$ www2.pucpr.br/reol/index.php/DIALOGO?dd1=7196\&dd99=pdf $>$. Acesso em 04 jan. 2017.

MEZZADRI, M. I ferri del mestiere. Corso di (auto) formazione per l'insegnante di lingua. Perugia: Guerra Edizioni, 2003.

OXFORD, R. Strategy Inventory for Language Learning - SILL. Disponível em: < https://richarddpetty.files.wordpress.com/2010/03/sill-english.pdf>. Acesso em 17 abr. 2018. 2006.

PAIVA, V. L. M. de O. Autonomia e complexidade. In: Linguagem e Ensino, Vol. 9, n 1, p.77-127,

VIEIRA, D. A. Dos estilos e estratégias de aprendizagem à didatização de materiais para o ensino do italiano língua estrangeira na pedagogia pós-método. 2017. 246 f. Tese (Doutorado) - Faculdade de 
Filosofia, Letras e Ciências Humanas da Universidade de São Paulo, São Paulo, 2017.

Recebido em: 14/09/2018

Aprovado em: 01/11/2018 